\title{
In-Structure Shock of Surface Structures: A Theoretical Approach
}

\author{
Hongyuan Zhou' and Xiaojuan Wang ${ }^{2}$ \\ ${ }^{1}$ School of Civil and Environmental Engineering, Nanyang Technological University, 50 Nanyang Avenue, Singapore 639798 \\ ${ }^{2}$ Department of Civil and Environmental Engineering, National University of Singapore, Singapore 117576 \\ Correspondence should be addressed to Xiaojuan Wang; ceewang@nus.edu.sg
}

Received 14 May 2015; Revised 6 July 2015; Accepted 7 July 2015

Academic Editor: Sakdirat Kaewunruen

Copyright (c) $2015 \mathrm{H}$. Zhou and X. Wang. This is an open access article distributed under the Creative Commons Attribution License, which permits unrestricted use, distribution, and reproduction in any medium, provided the original work is properly cited.

Metal foam cladding emerges as a promising measure for structure protection against close range blast. With proper cladding design, a considerable amount of energy can be absorbed while the load transmitted to the protected structure can be lowered to a controllable level, leading to less damage of the protected structure. However, it is not clear whether the in-structure shock can be mitigated by attaching foam cladding. The present study theoretically investigates the response of a structural member subjected to a close range blast, for both scenarios with and without attaching foam cladding. Subsequently, shock response spectra are employed to assess the in-structure shock of both situations. It is found that applying foam cladding does not effectively mitigate in-structure shock of surface structures.

\section{Introduction}

The protection of buildings and structures against accidental and terrorist attacks is of interest to scientific and engineering community. A traditional method to mitigate a blast load is to strengthen the structure itself. With thicker structural members and stronger reinforced materials, both the structural stiffness and strength are increased, leading to small deflection subjected to the same blast load. However, the drawbacks of strengthening do exist. With higher rigidity, the incident blast load is violently amplified, resulting in a higher load exerted on structures. Further, the construction and retrofit of such strengthened structures are expensive and timeconsuming. Recently, a new protection philosophy emerged: an additional cladding with metal foam core is attached to the target structure, which lowers the load transferred to the protected structure and meanwhile absorbs a considerable amount of energy, when subjected to the same blast load [1]. Sandwich panel behaviors are investigated and summarized [2], while energy absorption of various cellular structures and materials is examined [3]. Field test is conducted for aluminum foam core cladding protected concrete panels, and it is found that the protection is effective [4]. To ensure controllable constant load transmitted to the protected structure, cellular solid with relative density less than 0.2 should be applied [5]. When subjected to the same blast, the load transmitted to the protected structure is lowered while the cladding is crushed, which absorbs a large amount of energy. After that, the damage cladding is easily and quickly replaced with a new one; thus both resiliency and cost efficiency are achieved [6].

Generally, such a protective cladding is made of a face plate and a layer of metal foam or honeycomb as core. Subjected to rapid movement of the face plate induced by blasts, the foam adjacent to the face plate is crushed first; then the densification continues as a plastic shock wave [7]. In the upstream of the shock wave, metal foam remains almost undeformed and the load exerted on the protected structures is the foam plateau stress, which is adjustable by varying the foam relative density and considerably lower than the blast load.

While no doubt the structure protection in terms of strength is of importance, the mitigation effect in terms of vibration can never be ignored, especially when vibrationsensitive device is mounted or attached to the protected 

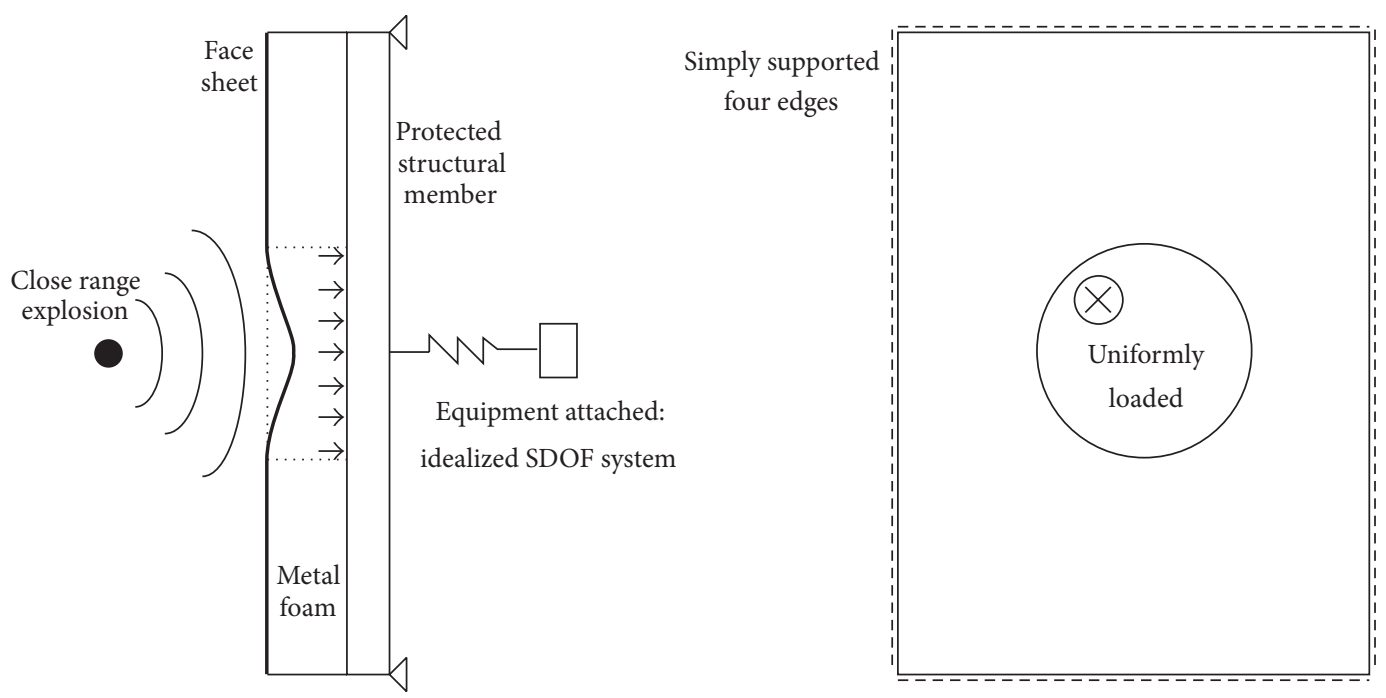

FIGURE 1: In-structure shock of surface structure with metal foam cladding subjected to close range blast.

structure. From the viewpoint of structural engineering, the strength aspect of protection is a matter of structural limit analysis while the vibration counterpart is an issue of serviceability. In-structure shock is a kind of strong vibration induced by an external blast or ballistic load not damaging or lightly damaging the main structure but causing devices within the structure to fail [8]. In-structure shock of underground structures with rigid body motion taken into account is investigated [9]. Double-layer floor is proposed to successfully mitigate vertical shock of underground structures [10]. Small scale test is conducted to validate the theoretical prediction of in-structure shock of underground structures [11]. Hybrid mounting system is tested [12]. In early years, instructure shock of surface structures is of minor significance since whether the structure can survive the explosion is the major concern. However, with the development of blast mitigation technology such as consolidation and attaching metal foam cladding, in some occasions, major damages of the protected structures can be avoided. Then the in-structure shock emerges as a problem of substantial significance. In the present study, in-structure shock assessment is performed for a surface structure with and without metal foam cladding subjected to a close range explosion, shown in Figure 1 [6]. Energy method can be used to determine the crater extent and depth. Then the crushing time history of the face plate (and the densified foam) is calculated, taken as the loading time for the protected structure. Subsequently, response of idealized structural member with cladding attached is obtained and compared to that without cladding protection. Finally, the in-structure shock of the structural member with and without cladding is examined.

\section{Response of Structural Member with Metal Foam Cladding Subjected to a Blast}

2.1. Time History of Foam Crushing. To obtain the duration of the load transmitted to the protected structural member from foam densification, crushing of the metal foam cladding subjected to a close range airburst is analyzed first. The cladding attached to the protected structure is a layer of metal foam covered by a thin solid face plate. When subjected to a blast load induced by a close range detonation, the nonuniform pressure will create a bulge, which is deepest in the point originally nearest to the explosion before deformation and its depth decreases towards the bulge periphery to zero. As shown in Figure 1, only the foam under the round bulge is crushed while the other foam remains undeformed [6].

The face plate of a typical blast mitigation cladding is a thin metallic plate. Bending does not contribute to the energy dissipation when the transverse deflection is greater than half of the plate thickness [13]. Subsequently, for sufficiently large deformation of a plate, the influence of the bending is ignored and the response is solely governed by membrane force. In the present study, the face plate is reasonably assumed as a rigid-plastic membrane under a close range explosion, as the face plate deflection is significantly larger than half of its thickness. Take the face plate and the densified form to analyze. Compared to the face plate, the stretching energy dissipation contribution of the metal foam core, both densified and undensified, is relatively small and can be neglected [14]. By equating the work rate by external load, inertia force, and foam resistance to the energy dissipation rate by the membrane stretching, the governing equation for the system consisting of the face plate and densified foam in the blast duration is

$$
\begin{gathered}
\int_{A}\left[p-\left(\rho_{b} h_{b}+\frac{\rho_{f}}{\varepsilon_{D}} w\right) \ddot{w}-\left(\sigma_{\mathrm{pl}}+\frac{\rho_{f}}{\varepsilon_{D}} \dot{w}^{2}\right)\right] \dot{w} d A \\
=\int_{A}\left(N_{r} \kappa_{r}+N_{\theta} \kappa_{\theta}\right) \dot{w} d A,
\end{gathered}
$$

where $p$ is the nonuniform blast load time history considering fluid-structure interaction; $\rho_{b}, h_{b}$ are the density and thickness of the face plate; $\rho_{f}, \sigma_{\mathrm{pl}}$, and $\varepsilon_{D}$ are the 
density, plateau stress, and densification strain of the foam, respectively; $w$ is the deflection of the face plate; and $N_{r}$ and $N_{\theta}$ are internal forces (in fact the internal force per unit length, according to the convention in plate theory) of the face plate in radial and circumferential direction. Recall [15]:

$$
\begin{gathered}
\kappa_{r}=\frac{\partial^{2} w}{\partial r^{2}} \kappa_{\theta}=\frac{1}{r} \frac{\partial w}{\partial r} \\
N_{r}=N_{\theta}=N_{0}=\sigma_{b} h_{b} .
\end{gathered}
$$

$r$ is the radius from the bulge center and $\sigma_{b}$ is the yield stress of the face plate. Equation (1) is recast as

$$
\begin{aligned}
& \int_{0}^{\eta}\left\{\left[p-\left(\rho_{b} h_{b}+\frac{\rho_{f}}{\varepsilon_{D}} w\right) \ddot{w}-\left(\sigma_{\mathrm{pl}}+\frac{\rho_{f}}{\varepsilon_{D}} \dot{w}^{2}\right)\right] \dot{w} r\right. \\
& \left.-\sigma_{b} h_{b}\left(\frac{\partial^{2} \dot{w}}{\partial r^{2}}+\frac{1}{r} \frac{\partial \dot{w}}{\partial r}\right) w r\right\} d r=0
\end{aligned}
$$

where $\eta=\sqrt{2} \sqrt{\ln \left(p_{c} / \sigma_{\mathrm{pl}}\right)}$ is the bulge extent [6], where $p_{c}$ is the peak reflected pressure on face plate defined in (6) later. The first term in the square brackets is the blast load applied on the face sheet, in fact the external driving force. The second term is the inertial force of the system consisting of the face plate and the fully densified foam part, in which $\rho_{b} h_{b}$ is the mass per unit area of the face plate and $\rho_{f} / \varepsilon_{D} w$ is the mass per unit area of the densified foam. The third term in the square brackets is the resistance from the dynamic foam crushing, including the foam plateau stress $\sigma_{\mathrm{pl}}$ (the quasi-static part) and the dynamic enhancement $\left(\rho_{f} / \varepsilon_{D}\right) \dot{w}^{2}$. Decouple the space and time of the face plate deflection time history:

$$
w(r, t)=W(r) T(t)=W_{0} e^{-r^{2} / 2 c^{2}} T(t),
$$

where $W(r)=W_{0} e^{-r^{2} / 2 c^{2}}$ is the bulge shape, $c$ is the characteristic dimension of the bugle, and $\eta=3 c$. Then the velocity and acceleration of the face sheet are

$$
\begin{aligned}
& \dot{w}(r, t)=W(r) \dot{T}(t), \\
& \ddot{w}(r, t)=W(r) \ddot{T}(t) .
\end{aligned}
$$

In the present study, the bell-shaped blast load is approximated as

$$
p(r, t)=p_{c} e^{-r^{2} / 2 b^{2}}\left(1-\frac{t}{T_{d}}\right)
$$

where $p_{c}$ is the peak reflected pressure on the face plate and $T_{d}$ is the blast duration. $b$ is the characteristic size of the loading region, the same as the standoff distance between the explosion and face plate. At $r=3 b$ the load decreases to $1 \%$ of the peak value and is neglected. This blast load distribution assumption agrees well with the measured load in test [6].
With (5), (3) is recast as

$$
\begin{aligned}
& \int_{0}^{\eta} r W(r)[p(r, t) \\
& -\left(\rho_{b} h_{b}+\frac{\rho_{f}}{\varepsilon_{D}} W(r) T(t)\right) W(r) \ddot{T}(t) \\
& \quad-\left(\sigma_{f}+\frac{\rho_{f}}{\varepsilon_{D}} W^{2}(r) \dot{T}^{2}(t)\right) \\
& \left.-\sigma_{b} h_{b} W(r) T(t)\left(\frac{r^{2}}{c^{4}}-\frac{2}{c^{2}}\right)\right] d r=0 .
\end{aligned}
$$

Substitute (4) and (6) into (7) and integrate it:

$$
\begin{aligned}
\frac{c^{2}}{3} \frac{\rho_{f}}{\varepsilon_{D}} & W_{0}^{2}\left(1-e^{-3 \eta^{2} / 2 c^{2}}\right)\left[\ddot{T}(t) T(t)+\dot{T}^{2}(t)\right] \\
& +\frac{1}{2} c^{2} W_{0} \rho_{b} h_{b}\left(1-e^{-\eta^{2} / c^{2}}\right) \ddot{T}(t) \\
& +\frac{1}{2} \sigma_{b} h_{b} W_{0}\left[1-\left(1-\frac{\eta^{2}}{c^{2}}\right) e^{-\eta^{2} / c^{2}}\right] T(t) \\
= & \frac{b^{2} c^{2}}{b^{2}+c^{2}} p_{c}\left(1-e^{-\left(\left(b^{2}+c^{2}\right) / 2 b^{2} c^{2}\right) \eta^{2}}\right)\left(1-\frac{t}{T_{d}}\right) \\
& -c^{2} \sigma_{\mathrm{pl}}\left(1-e^{-\eta^{2} / 2 c^{2}}\right)
\end{aligned}
$$

In short term,

$$
\begin{aligned}
& \ddot{T}(t) T(t)+\dot{T}^{2}(t)+F \ddot{T}(t)+G T(t) \\
& =H\left(1-\frac{t}{T_{d}}\right)+I
\end{aligned}
$$

where

$$
\begin{aligned}
& F=\frac{3 \rho_{b} h_{b} \varepsilon_{D}}{2 \rho_{f} W_{0}}, \\
& G=\frac{3 \sigma_{b} h_{b} \varepsilon_{D}}{2 c^{2} \rho_{f} W_{0}}, \\
& H=\frac{3 b^{2} p_{c} \varepsilon_{D}\left[1-e^{-9\left(b^{2}+c^{2}\right) / 2 b^{2}}\right]}{\rho_{f} W_{0}^{2}\left(b^{2}+c^{2}\right)}, \\
& I=-\frac{3 \sigma_{\mathrm{pl}} \varepsilon_{D}}{\rho_{f} W_{0}^{2}} .
\end{aligned}
$$

It is worth noting that the coefficients in (9) are simplified by neglecting the trivially small items using the relation $\eta=$ $3 c$. Equation (9) is a nonlinear ordinary differential equation and its solution cannot be analytically obtained due to the presence of the square item. Four-order Runge-Kutta method is adopted to numerically solve the governing equation for $T(t)$.

If the blast load is relatively weak compared to the resistance from the face plate and metal foam, the crushing 


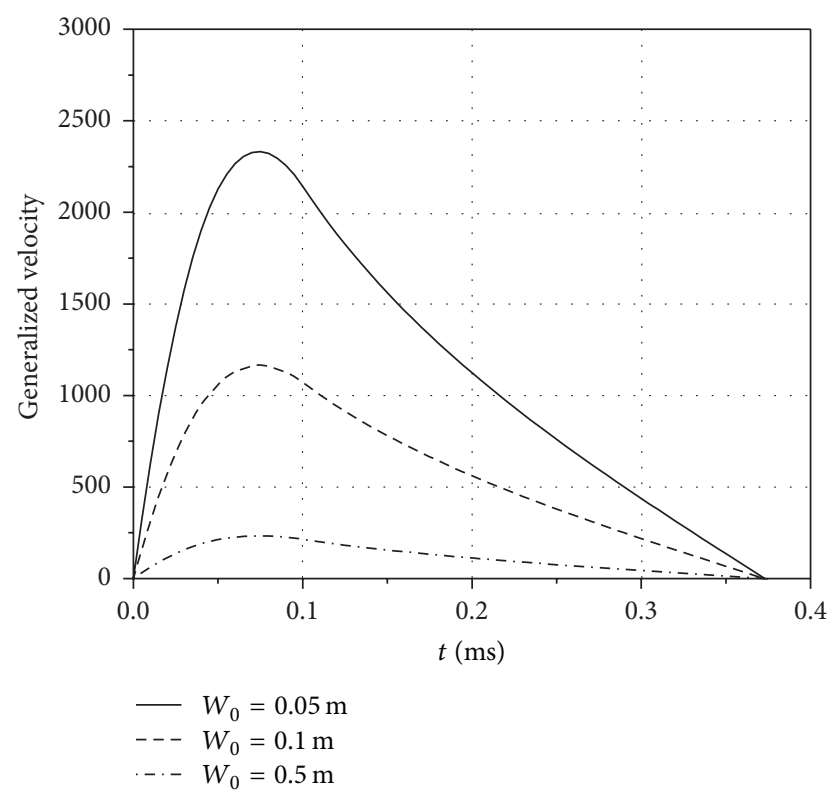

Figure 2: The total crushing time does not depend on the bulge depth.

may cease in the blast duration. However, for a typical close range explosion, the blast intensity is substantially higher than the resistance, where a relatively larger amount of energy is imparted into the cladding resulting in a crushing period longer than the blast duration. Generally, the blast load duration induced by a close range airburst varies in the order of 0.1 milliseconds or less and the structural response may be several times longer. After the blast load, there is no external loading on the cladding. Offset the time by $T_{d}$, let $t_{1}=t-T_{d}$, and the governing equation after blast is

$$
\ddot{T}\left(t_{1}\right) T\left(t_{1}\right)+\dot{T}^{2}\left(t_{1}\right)+F \ddot{T}\left(t_{1}\right)+G T\left(t_{1}\right)=I .
$$

The initial condition of the second phase is the terminal response of the blast duration to ensure the continuity of the displacement and velocity:

$$
\begin{aligned}
& T\left(t_{1}=0\right)=T\left(t=T_{d}\right)=P, \\
& \dot{T}\left(t_{1}=0\right)=\dot{T}\left(t=T_{d}\right)=Q .
\end{aligned}
$$

Again, combine the governing equation and the initial condition for the second phase, and the Runge-Kutta method is employed to solve (11).

When the face plate velocity decreases to zero at $t_{1}=t_{f}$, the foam crushing ceases. $t_{f}$ is determined by intersecting the generalized velocity, $\dot{T}(t)$, with time axis. Finally the entire foam crushing duration due to the close range explosion is

$$
T_{\text {total }}=T_{d}+t_{f}
$$

where $t_{f}$ is the instant of crushing stops with respect to time starting from $T_{d}$.

It is worth noting from coefficient of (9) and (11) that the crushing time depends not only on the blast load and cladding parameters but also on the final bulge depth, which in fact is also a function of the blast and cladding parameters. However, the numerical predictions of (9) and (11) indicate that the crushing time of the cladding is independent of the bulge depth, as shown in Figure 2: when the blast load and cladding parameters are the same, the crushing duration is the same in spite of the different bulge depths arbitrarily assigned. The only purpose of the crushing time history analysis is to determine the total crushing time. Therefore, the bulge depth is not necessarily in its true value and set as unity (although not practical in engineering practice) in the present study.

According to the shock theory for foam $[2,3,7]$, the crushing process in fact is a plastic wave propagation process, shown in Figure 3. Downstream of the shock front, the foam is densified with high stress and strain while, upstream of the shock front, the uncrushed foam is in elastic compression with foam plateau stress [2]. Therefore no matter how strong the load is applied on the face plate, the load transmitted to the protected structure is the foam plateau stress, provided that the foam is not totally crushed. Total crush of the foam layer may result in a load even higher than the blast load on face plate and should be avoided.

Consider that a structural member of a building is protected by attaching a metal foam cladding, subjected to a close range spherical detonation. The member is loaded by the foam in a round region due to the axis symmetry of the close spherical explosion, indicated in Figure 1. The boundary of the structural member is connected to adjacent slabs, neither simply supported nor fixed. In the present study, it is considered as simply supported at four edges, leading to a conservative prediction, safe in design.

2.2. Equivalent SDOF System for a Simply Supported Rectangular Structural Member. Subjected to a dynamic load, analytical solution for continuous system is generally difficult 


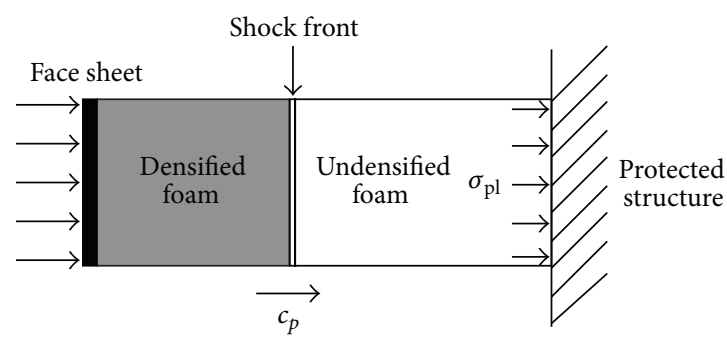

FIGURE 3: Foam crushing in progressive collapse mode and load transmitted to the protected structure.

and cumbersome to obtain, especially when the load is nonuniformly distributed on a part of the structure. To analyze a continuous system under dynamic load in a relatively simple way with adequate accuracy, a single-degree-offreedom (SDOF) equivalent method for continuous systems is frequently adopted [16]. In the idealization, the time scale is not altered; therefore the response time history of the idealized system is exactly the same as that of the real structure. Before idealization, the deformation profile of the structural member must be predefined. Various approximate deflection modes can be chosen for the simply supported rectangular plate; in the present study, the fundamental deflection mode is adopted. If higher analysis accuracy is required, higher order deformation modes can be also incorporated, however, with higher analysis cost.

According to Biggs [16], the equivalent mass of the rectangular plate is calculated:

$$
\begin{aligned}
M_{e} & =\int_{A} m(x, y) \phi^{2}(x, y) d A \\
& =\rho_{s} h_{s} \int_{0}^{b} \int_{0}^{a} \sin ^{2} \frac{\pi x}{a} \sin ^{2} \frac{\pi y}{b} d x d y=\frac{1}{4} \rho_{s} h_{s} a b,
\end{aligned}
$$

where $a, b, \rho_{s}$, and $h_{s}$ are the two edge dimensions, density, and thickness of the structural member, respectively. $\phi(x, y)$ is the approximate deformation profile, taken as $\phi(x, y)=$ $\sin (\pi x / a) \sin (\pi y / b)$, where the origin of the coordinates is taken as one of the plate corners. The transformation factor for mass is

$$
K_{M}=\frac{M_{e}}{M_{r}}=\frac{(1 / 4) \rho_{s} h_{s} a b}{\rho_{s} h_{s} a b}=\frac{1}{4} .
$$

The subscripts $e$ and $r$ denote "equivalent" and "real," respectively. In calculating the equivalent load, double cosine function, instead of double sine function, is employed with coordinate shift while keeping the idealization nature exactly unchanged:

$$
\begin{aligned}
& F_{e 1}=\int_{A} p(x, y, t) \phi(x, y) d A \\
& \quad=4 \sigma_{\mathrm{pl}}\left(1-\frac{t}{T_{\text {total }}}\right) \int_{0}^{\eta} \int_{0}^{\sqrt{\eta^{2}-x^{2}}} \cos \frac{\pi x}{a} \cos \frac{\pi y}{b} d y d x,
\end{aligned}
$$

where $\eta=3 c$ is the bulge extent. The corresponding real load is

$$
F_{r 1}=\sigma_{\mathrm{pl}} \pi \eta^{2}\left(1-\frac{t}{T_{\text {total }}}\right) .
$$

However, (16) cannot be analytically integrated and thus evaluated numerically. The transformation factor for this load is

$$
\begin{aligned}
K_{L 1} & =\frac{F_{e 1}}{F_{r 1}} \\
& =\frac{4 \int_{0}^{\eta} \int_{0}^{\sqrt{\eta^{2}-x^{2}}} \cos (\pi x / a) \cos (\pi y / b) d y d x}{\pi \eta^{2}} .
\end{aligned}
$$

The transformation factor for stiffness is exactly the same as that for load [16]; therefore the equivalent stiffness is

$$
k_{e 1}=k_{r 1} K_{L 1}
$$

$k_{r 1}$ is the stiffness of the rectangular plate with four edges simply supported which is calculated as follows. Generally, stiffness of a structural member is defined as the force necessary to cause a unit deflection at the point of interest or the ratio of force applied to the deflection caused. For a continuous structural member such as a plate in the present study, to determine the stiffness, the area of loading must be considered. Specifically, a concentrated load on the plate center causes larger deflection at this point, resulting in smaller plate stiffness; when the concentrated force is uniformly distrusted over the whole plate surface with total force exactly the same, the deflection at the plate center is relatively smaller; thus the plate appears stiffer. Therefore, within the elastic limit, although the stiffness is not a function of loading intensity, it is a function of the loading pattern or area in terms of the above-mentioned stiffness definition. Then the plate stiffness with central round loading area in the present study (the most critical case is loaded in the center) should be between the two cases mentioned above. The deflection for a simply supported rectangular plate 
subjected to uniform load on a circle region around the center is

$$
\begin{aligned}
w_{1} & =\frac{1}{\pi^{4} D} \\
\cdot & \sum_{m=1}^{\infty} \sum_{n=1}^{\infty} \frac{a_{m n}}{\left(\left(m^{2} / a^{2}\right)+\left(n^{2} / b^{2}\right)\right)^{2}} \sin \frac{m \pi x}{a} \sin \frac{n \pi y}{b},
\end{aligned}
$$

where

$$
a_{m n}=\frac{16}{a b} \int_{0}^{\eta} \int_{0}^{\sqrt{\eta^{2}-x^{2}}} \sigma_{\mathrm{pl}} \sin \frac{m \pi x}{a} \sin \frac{n \pi y}{b} d y d x .
$$

$D=E h_{s}^{3} /\left[12\left(1-v^{2}\right)\right]$ is the bending rigidity of the plate. It is worth noting that the series in (20) converge quickly and only first five terms can achieve adequate accuracy [15]. The real stiffness of the structural member is

$$
k_{r 1}=\frac{F_{r 1}}{w_{1}} .
$$

Until now, the equivalent mass, load, and stiffness are calculated and the equivalent natural frequency of the idealized SDOF system is

$$
\omega_{e 1}=\sqrt{\frac{k_{e 1}}{M_{e}}}
$$

2.3. Response of the Structural Member with Metal Foam Cladding. With metal foam cladding attached, the load exerted on the structural member is the foam plateau stress and the loading duration is the period of cladding crushing. The governing equation for the structural member within blast duration is

$$
M_{e} \ddot{y}_{1}(t)+c_{e 1} \dot{y}_{1}(t)+k_{e 1} y_{1}(t)=F_{1}\left(1-\frac{t}{T_{\text {total }}}\right) .
$$

The damping ratio $\xi_{1}=c_{e 1} /\left(2 \omega_{e 1} M_{e 1}\right)$ is taken as $5 \%$ of the critical, typical for surface structures [17]. With initial conditions of zero displacement and velocity, the displacement and acceleration time history of the structural member center are

$$
\begin{aligned}
& \left\{\begin{array}{l}
y_{1}(t) \\
\ddot{y}_{1}(t)
\end{array}\right\}=\frac{F_{1}}{k_{e 1}}\left(e^{-\xi_{1} \omega_{e 1} t} \mathbf{M}_{1}\left\{\begin{array}{l}
\cos \left(\sqrt{1-\xi_{1}^{2}} \omega_{e 1} t\right) \\
\sin \left(\sqrt{1-\xi_{1}^{2}} \omega_{e 1} t\right)
\end{array}\right\}\right. \\
& \left.+\left\{1-\frac{t}{T_{\text {total }}}+\frac{2 \xi_{1}}{\omega_{e 1} T_{\text {total }}}\right\}\right),
\end{aligned}
$$

where

$$
\begin{aligned}
& \mathbf{M}_{1}=\left[\begin{array}{cc}
-\left(1+\frac{2 \xi_{1}}{\omega_{e 1} T_{\text {total }}}\right) & \frac{1}{\sqrt{1-\xi_{1}^{2}} \omega_{e 1} T_{\text {total }}}\left[1-\omega_{e 1} \xi_{1}\left(T_{\text {total }}+\frac{2 \xi_{1}}{\omega_{e 1}}\right)\right] \\
\frac{\omega_{e 1}}{\sqrt{1-\xi_{1}^{2}} T_{\text {total }}}\left[-1+8 \xi_{1}^{2}\left(1-\xi_{1}^{2}\right)+\omega_{e 1} T_{\text {total }} \xi_{1}\left(3-4 \xi_{1}^{2}\right)\right] & {\left[1-2 \xi_{1}^{2}+\frac{4 \xi_{1}\left(1-\xi_{1}^{2}\right)}{\omega_{e 1} T_{\text {total }}}\right]}
\end{array}\right], \\
& F_{1}=4 \sigma_{\mathrm{pl}} \int_{0}^{\eta} \int_{0}^{\sqrt{\eta^{2}-x^{2}}} \cos \frac{\pi x}{a} \cos \frac{\pi y}{b} d y d x .
\end{aligned}
$$

In the postloading phase, the structural member undergoes free vibration until the motion is damped out, which also contributes to the in-structure shock. Offset time by the cladding crushing duration: $t_{2}=t-T_{\text {total }}$. The response time history in the free vibration phase is

$$
\left\{\begin{array}{l}
y_{1}\left(t_{2}\right) \\
\ddot{y}_{1}\left(t_{2}\right)
\end{array}\right\}=e^{-\xi_{1} \omega_{e 1} t_{2}} \mathbf{M}_{2}\left\{\begin{array}{c}
\cos \left(\sqrt{1-\xi_{1}^{2}} \omega_{e 1} t_{2}\right) \\
\sin \left(\sqrt{1-\xi_{1}^{2}} \omega_{e 1} t_{2}\right)
\end{array}\right\},
$$

where

$$
\mathbf{M}_{2}=\left[\begin{array}{c}
R_{1} \\
\omega_{e 1}^{2}\left[\left(2 \xi_{1}^{2}-1\right) R_{1}-2 \xi_{1}\left(\xi_{1} R_{1}+\frac{S_{1}}{\omega_{e 1}}\right)\right] \omega_{e 1}^{2}\left[2 \xi_{1} \sqrt{1-\xi_{1}^{2}} R_{1}+\frac{2 \xi_{1}^{2}-1}{\sqrt{1-\xi_{1}^{2}}}\left(\xi_{1} R_{1}+\frac{S_{1}}{\omega_{e 1}}\right)\right]
\end{array}\right],
$$


where $y_{1}\left(t=T_{\text {total }}\right)=R_{1}, \dot{y}_{1}\left(t=T_{\text {total }}\right)=S_{1}$ are the initial conditions for the free vibration phase ensuing the continuity of the displacement and velocity.

\section{Response of Structural Member without Cladding Subjected to a Blast}

Without cladding, for the same detonation, the scaled distance is larger due to the absence of the cladding thickness, resulting in a smaller loading intensity and a larger loading area, compared to the load on the face plate.

The real load on the structural member (within the bulge) is

$$
\begin{aligned}
F_{r 2} & =\int_{A} p(r, t) d A=\int_{0}^{\eta} p_{c 2} e^{-r^{2} / 2 b^{2}}\left(1-\frac{t}{T_{d}}\right) 2 \pi r d r \\
& =\frac{2}{9} \pi \eta^{2} p_{c}\left(1-\frac{t}{T_{d}}\right) .
\end{aligned}
$$

With the same idealization method for the load on structural member as briefed in the preceding section, the equivalent load is

$$
\begin{aligned}
F_{e 2} & =\int_{A} p(x, y, t) \phi(x, y) d A=4\left(1-\frac{t}{T_{d}}\right) \\
\cdot & \int_{0}^{\eta} \int_{0}^{\sqrt{\eta^{2}-x^{2}}} p_{c 2} e^{-\left(x^{2}+y^{2}\right) / 2 b^{2}} \cos \frac{\pi x}{a} \cos \frac{\pi y}{b} d y d x .
\end{aligned}
$$

The transformation factor for load is

$$
K_{L 2}=\frac{F_{e 2}}{F_{r 2}} .
$$

It should be noted that, in the present study, only the load within the bulge is considered, for both the cases with and without foam cladding attached. In so doing, the response can be compared without considering the load outside the bulge, based on the principle of superposition of elastic systems (the structural member is assumed elastic).

Assume that the structural member is statically loaded with the peak load of time zero, and the static deflection at the center is

$$
\begin{aligned}
w_{2} & =\frac{1}{\pi^{4} D} \\
& \cdot \sum_{m=1}^{\infty} \sum_{n=1}^{\infty} \frac{a_{m n}}{\left(\left(m^{2} / a^{2}\right)+\left(n^{2} / b^{2}\right)\right)^{2}} \sin \frac{m \pi x}{a} \sin \frac{n \pi y}{b},
\end{aligned}
$$

where

$$
\begin{aligned}
& a_{m n}=\frac{16}{a b} \int_{0}^{\eta} \int_{0}^{\sqrt{\eta^{2}-x^{2}}} p_{c} e^{-\left(x^{2}+y^{2}\right) / 2 b^{2}} \sin \frac{m \pi x}{a} \\
& \cdot \sin \frac{n \pi y}{b} d y d x .
\end{aligned}
$$

Then the stiffness is determined:

$$
k_{r 2}=\frac{F_{r 2}}{w_{2}} .
$$

Subsequently, the natural frequency of the equivalent system is

$$
\omega_{e 2}=\sqrt{\frac{k_{e 2}}{M_{e}}}
$$

Although a typical damping does not have significant influence on the structural response within the short blast duration, it has significant influence on the free vibration phase [17]. A typical damping of $5 \%$ critical in structural response [17] is used in both phases for consistence. The governing equation for the structural member within the blast duration is

$$
M_{e} \ddot{y}_{2}(t)+c_{e 2} \dot{y}_{2}(t)+k_{e 2} y_{2}(t)=F_{e 2}\left(1-\frac{t}{T_{d}}\right) .
$$

With zero initial conditions, the structural response at the center is

$$
\begin{aligned}
& \left\{\begin{array}{l}
y_{2}(t) \\
\ddot{y}_{2}(t)
\end{array}\right\}=\frac{F_{e 2}}{k_{e 2}}\left(e^{-\xi_{2} \omega_{e 2} t} \mathbf{M}_{3}\left\{\begin{array}{c}
\cos \left(\sqrt{1-\xi_{2}^{2}} \omega_{e 2} t\right) \\
\sin \left(\sqrt{1-\xi_{2}^{2}} \omega_{e 2} t\right)
\end{array}\right\}\right. \\
& +\left\{\begin{array}{c}
\left.\left.1-\frac{t}{T_{d}}+\frac{2 \xi_{2}}{\omega_{e 2} T_{d}}\right\}\right), \\
0
\end{array}\right.
\end{aligned}
$$

where

$$
\mathbf{M}_{3}=\left[\begin{array}{cc}
-\left(1+\frac{2 \xi_{2}}{\omega_{e 2} T_{d}}\right) & \frac{1}{\sqrt{1-\xi_{2}^{2}} \omega_{e 2} T_{d}}\left[1-\omega_{e 2} \xi_{2}\left(T_{d}+\frac{2 \xi_{2}}{\omega_{e 2}}\right)\right] \\
\frac{\omega_{e 2}}{\sqrt{1-\xi_{2}^{2} T_{d}}}\left[-1+8 \xi_{2}^{2}\left(1-\xi_{2}^{2}\right)+\omega_{e 2} T_{d} \xi_{2}\left(3-4 \xi_{2}^{2}\right)\right] & {\left[1-2 \xi_{2}^{2}+\frac{4 \xi_{2}\left(1-\xi_{2}^{2}\right)}{\omega_{e 2} T_{d}}\right]}
\end{array}\right] .
$$




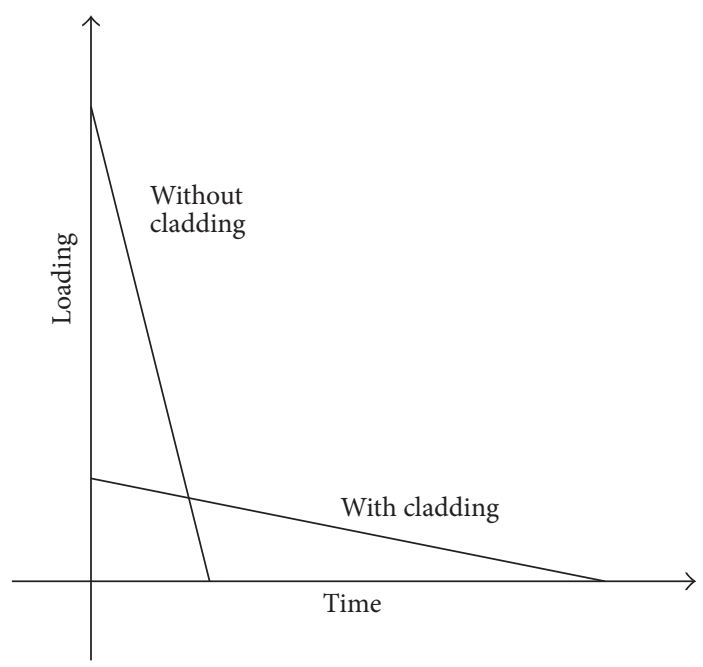

FIGURE 4: Load on structure comparison with and without cladding.

It is worth noting that the loading intensity is smaller than that on the face plate due to the larger standoff distance when the cladding is not attached. The response in the postblast phase is a damped vibration:

$$
\begin{aligned}
& \left\{\begin{array}{l}
y_{2}\left(t_{3}\right) \\
\ddot{y}_{2}\left(t_{3}\right)
\end{array}\right\}=e^{-\xi_{2} \omega_{e 2} t_{3}} \mathbf{M}_{4}\left\{\begin{array}{c}
\cos \left(\sqrt{1-\xi_{2}^{2}} \omega_{e 2} t_{3}\right) \\
\sin \left(\sqrt{1-\xi_{2}^{2}} \omega_{e 2} t_{3}\right)
\end{array}\right\}, \\
& \mathbf{M}_{4}=\left[\begin{array}{c}
R_{2} \\
\omega_{e 2}^{2}\left[\left(2 \xi_{2}^{2}-1\right) R_{2}-2 \xi_{2}\left(\xi_{2} R_{2}+\frac{S_{2}}{\omega_{e 2}}\right)\right] \omega_{e 2}^{2}\left[2 \xi_{2} \sqrt{1-\xi_{2}^{2}} R_{2}+\frac{2 \xi_{2}^{2}-1}{\sqrt{1-\xi_{2}^{2}}}\left(\xi_{2} R_{2}+\frac{S_{2}}{\omega_{e 2}}\right)\right]
\end{array}\right],
\end{aligned}
$$

where $y_{2}\left(t=T_{d}\right)=R_{2}, \dot{y}_{2}\left(t=T_{d}\right)=S_{2}$ are the initial conditions for the postblast phase ensuring the continuity of the displacement and velocity between the two phases.

\section{In-Structure Shock Assessment with a Case Study}

A typical event is considered as a case study. Assume a spherical explosive with TNT equivalent charge of $0.157 \mathrm{~kg}$ detonated $0.3 \mathrm{~m}$ away from the face plate, producing a blast with duration of $0.1 \mathrm{~ms}$ and a peak pressure of $8 \mathrm{MPa}$ (directly read from the chart in [18]). The face plate is made of aluminum with thickness $1 \mathrm{~mm}$, while aluminum foam with relative density of $5 \%$ is used as cladding core, having a plateau stress of $0.67 \mathrm{MPa}$. The thickness of the cladding is assumed as $5 \mathrm{~cm}$; thus if the cladding is absent, the standoff distance from the explosion to the structural member is $0.35 \mathrm{~m}$. With the same explosive charge and larger standoff distance, the peak load on the structural member reduced to $5.1 \mathrm{MPa}$ in the present study and the loading area is larger with radius $1.05 \mathrm{~m}$. However, the blast duration is assumed the same as in the case with cladding, $0.1 \mathrm{~ms}$.

By attaching the metal foam cladding, the load experienced by the structure is shifted: without the cladding, the load is a narrow and high triangular pulse while, with cladding, it becomes a triangle with a lower intensity and a longer duration being the foam crushing time. Figure 4 illustrates the blast load applied on the face plate and the load transmitted to the protected structures (the load is defined as resultant force). Although both loads are triangles with different peak values and durations, the mechanisms are different: without cladding, the loading intensity decreases with loading area unchanged while, with cladding, the loading area decreases with the loading intensity unchanged being the foam plateau stress.

The structural member is a simply supported concrete plate of $2 \mathrm{~m}$ by $3 \mathrm{~m}$, with a thickness of $0.2 \mathrm{~m}$. Young's modulus and Poisson's ratio are $30 \mathrm{GPa}$ and 0.2 , respectively. From (22) and (35), the equivalent circular natural frequencies of the two idealized SDOF systems in the case study 


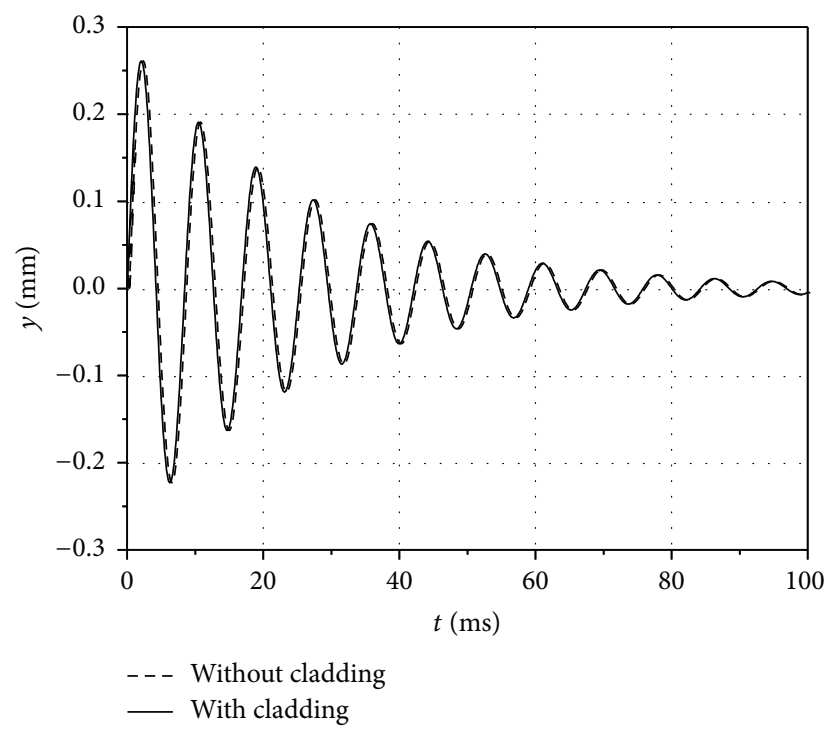

(a)

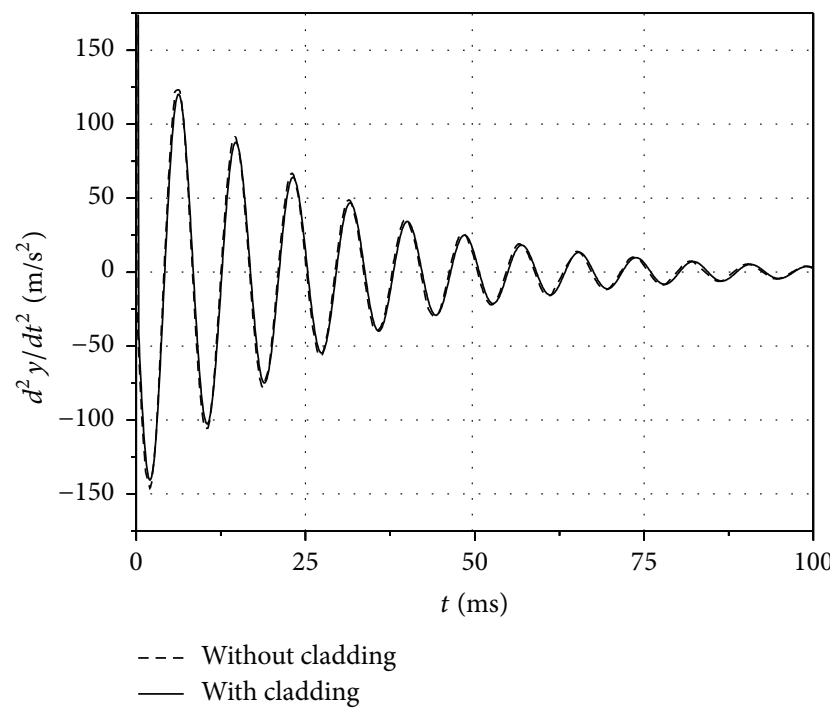

(b)

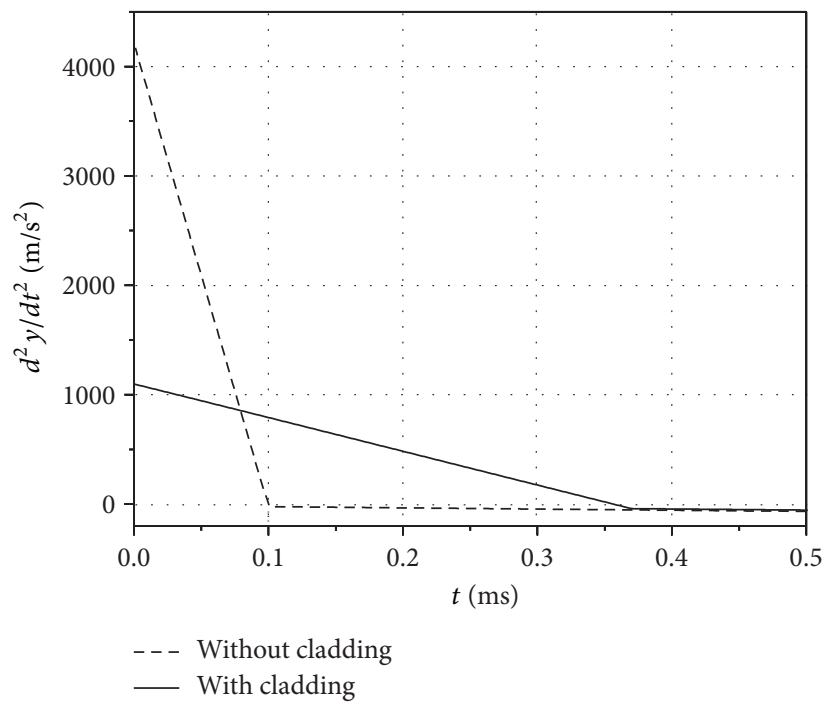

(c)

FIGURE 5: Structural member center response comparison with and without cladding. The blast duration is $0.1 \mathrm{~ms}$ and peak pressure is $8 \mathrm{MPa}$ on cladding and 5.12 MPa on structure without cladding: (a) displacements; (b) accelerations with initial stage truncated; (c) accelerations in the initial stage.

are similar: one is $317 \mathrm{rad} / \mathrm{s}$ and the other is $318 \mathrm{rad} / \mathrm{s}$. The equivalent mass is exactly the same for both idealizations. For the structural member without cladding, due to the larger standoff distance, the loading area is larger but the bellshaped loading concentrates in the central area while, for the same structural member with cladding, the loading area is smaller, but the foam crushing induced loading uniformly distributes in this area. Regarding the definition of the effective stiffness, with equivalent stiffness almost the same, the equivalent natural frequencies of the two SDOF systems are similar.

In the case study, when the peak load of the close range airburst is mediate, for instance, $8 \mathrm{MPa}$, the mitigation effect of the cladding is negligible, as shown in Figure 5. When the peak load increases to a relatively high value by increasing the explosive charge, $20 \mathrm{MPa}$, the mitigation effect is still not remarkable, indicated in Figure 6. Further, parametric study shows that the foam crushing duration increases with the peak blast load, shown in Figure 7. In addition, the ratio of foam crushing duration to blast duration decreases with increasing blast duration, shown in Figure 8 .

The responses of a structural member with and without metal foam cladding are analyzed, which are in fact the excitation for the equipment or devices attached to this member. A device, with its support, can be simplified as an SDOF system consisting of a spring, a damper, and a mass. The excitation for this SDOF system is similar to the one frequently used in earthquake engineering, where the 


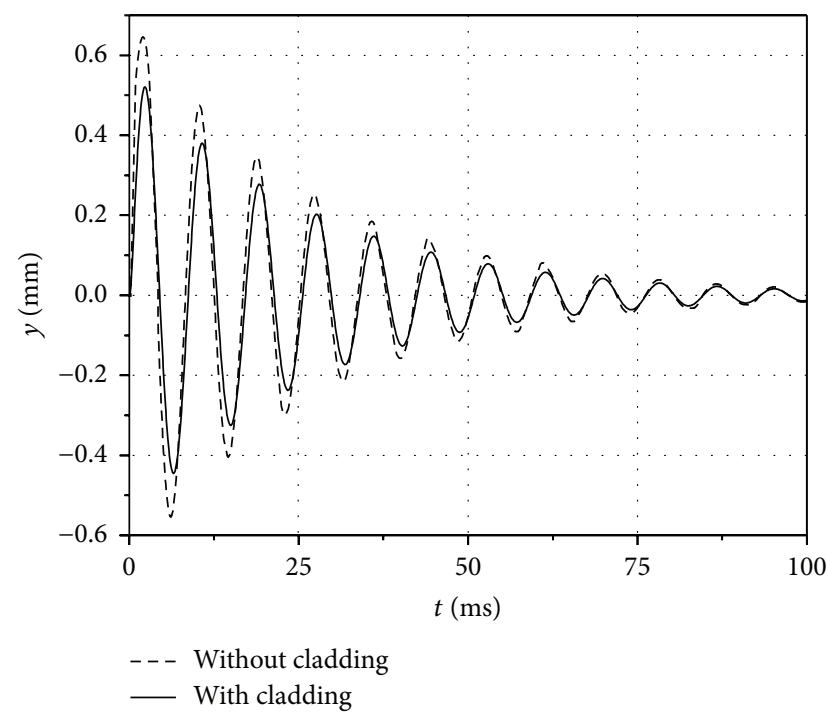

(a)

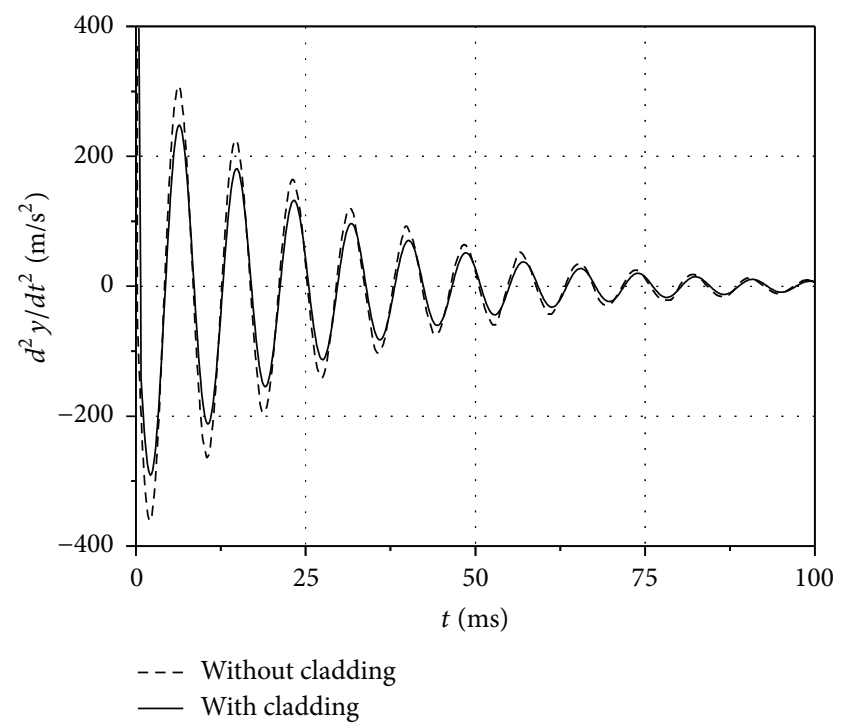

(b)

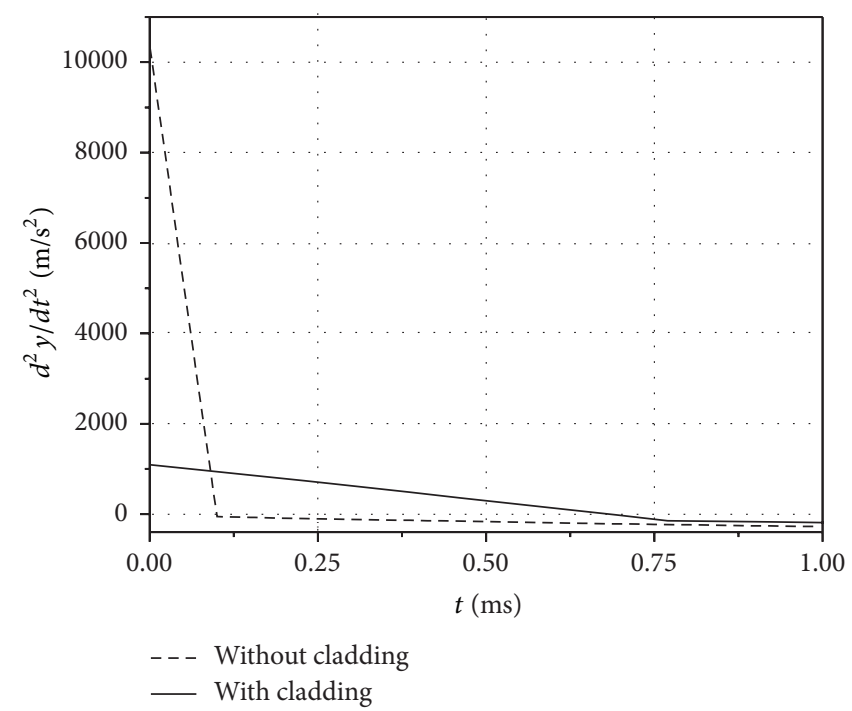

(c)

FIGURE 6: Structural member center response comparison with and without cladding. The blast duration is $0.1 \mathrm{~ms}$ and peak pressure is $20 \mathrm{MPa}$ on cladding and 12.6 MPa on structure without cladding: (a) displacements; (b) accelerations with initial stage truncated; (c) accelerations in the initial stage.

time history of base acceleration is the excitation to the attached systems. The response of the SDOF system depends on the characteristics of the excitation acceleration time history, natural frequency, and damping ratio (conventionally taken as zero for short duration load [17]) of the system. Then for a specific device with support, with zero initial condition, the responses such as displacement, velocity, and acceleration time histories can be determined. Subsequently, the maximum displacement, velocity, and acceleration are obtained. If the peak acceleration of certain device is greater than its corresponding tolerance, damage occurs [18].

The mass and stiffness characteristics of a specific device, with its mounting, can be delineated by one parameter: natural frequency or natural period. Therefore an SDOF system with varying natural frequency can represent a series of devices with supports. Shock response spectra are plots of the maximum responses of a series of SDOF systems subjected to the same excitation. When the excitation is prescribed, the maximum displacement, velocity, and acceleration can be read from the tripartite plot in different directions. Figure 9 indicates that when subjected to a close range detonation with peak loading pressure $8 \mathrm{MPa}$, the in-structure shock experienced by the devices mounted to the structural member is almost the same, regardless whether the metal foam cladding (of thickness $5 \mathrm{~cm}$ ) is attached or not. When the peak loading is increased to $20 \mathrm{MPa}$ while other parameters are unchanged, the shock level of the device is slightly (not remarkable) smaller for cladding-applied structural member 


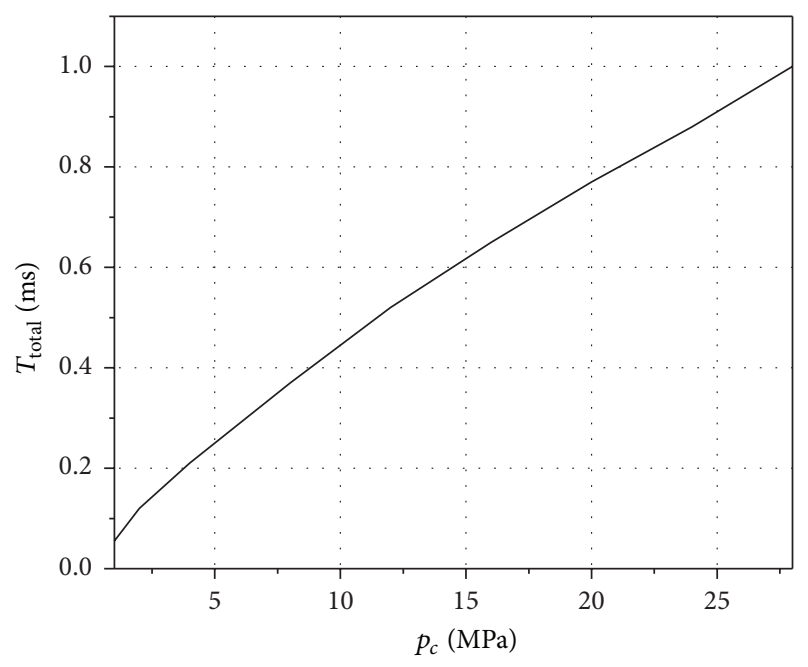

FIGURE 7: Relationship between the peak pressure and the crushing duration.

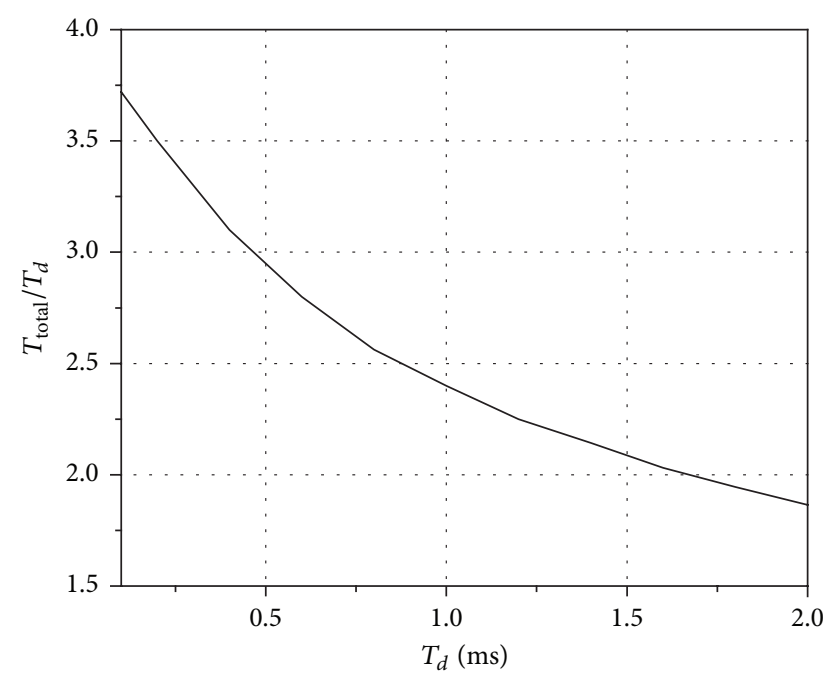

Figure 8: Ratio of the crushing time to blast duration.

compared to that without cladding, as shown in Figure 10. To sum up, attaching foam cladding to structural member does not mitigate the in-structure shock of surface structures.

\section{Conclusions}

A procedure for evaluating the in-structure shock of surface structures is proposed. By attaching a metal foam cladding to a structural member, the loading exerted on the member is altered from a pulse with a higher peak and a shorter duration to a pulse with a lower peak and a longer duration, although the pulses are both triangular. Due to the similar impulses imparted to the structural member and the relatively short loading durations, although elongated in the case with cladding, compared to the natural period of the member, the responses including the displacement and acceleration time histories are similar with and without the cladding. Attaching

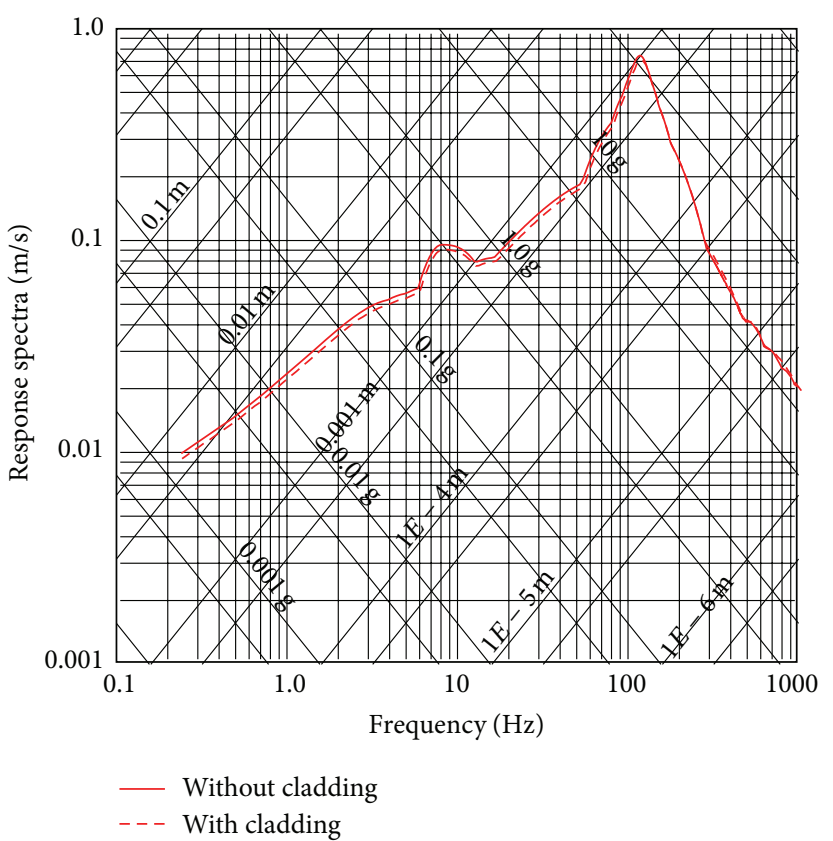

FIGURE 9: Shock response spectra with cladding subjected to a blast load with peak pressure $8 \mathrm{MPa}$ on cladding and $5.122 \mathrm{MPa}$ on structure, with both durations being $0.1 \mathrm{~ms}$.

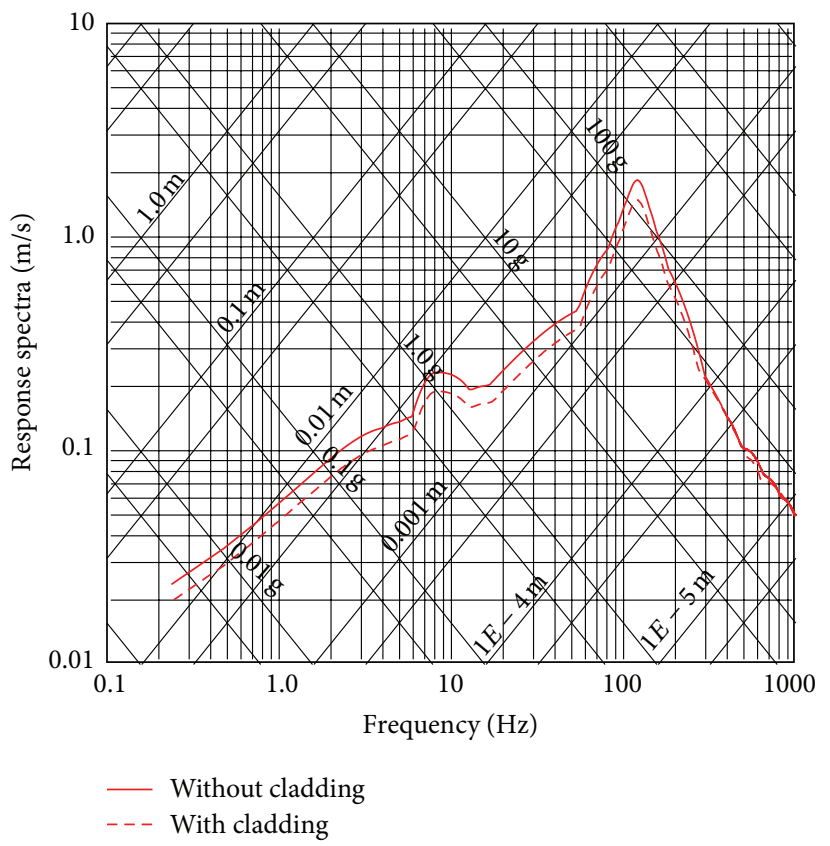

FIGURE 10: Shock response spectra with cladding subjected to a blast load with peak pressure $20 \mathrm{MPa}$ on cladding and $12.6 \mathrm{MPa}$ on structure, with both durations being $0.1 \mathrm{~ms}$.

foam cladding in structural protection against blast does not mitigate in-structure shock.

\section{Conflict of Interests}

The authors declare that there is no conflict of interests regarding the publication of this paper. 


\section{References}

[1] P. Zhang, Y. Cheng, and J. Liu, "Numerical analysis of dynamic response of corrugated core sandwich panels subjected to nearfield air blast loading," Shock and Vibration, vol. 2014, Article ID 180674, 16 pages, 2014.

[2] M. F. Ashby, A. Evans, N. A. Fleck, L. G. Gibson, J. W. Hutchinson, and H. N. G. Wadley, Metal Foam: A Design Guide, Butterworth-Heinemann, 2000.

[3] G. X. Lu and T. X. Yu, Energy Absorption of Structures and Materials, CRC Press, Boca Raton, Fla, USA, 2003.

[4] C. Q. Wu, L. Huang, and D. J. Oehlers, "Blast testing of aluminum foam-protected reinforced concrete slabs," Journal of Performance of Constructed Facilities, vol. 25, no. 5, pp. 464-474, 2011.

[5] L. J. Gibson and M. F. Ashby, Cellular Solids: Structures and Properties, Cambridge University Press, Cambridge, UK, 2nd edition, 1997.

[6] H. Y. Zhou, G. W. Ma, J. D. Li, and Z. Y. Zhao, "Design of metal foam cladding subjected to close-range blast," Journal of Performance of Constructed Facilities, Article ID 04014110, 2014.

[7] S. R. Reid and C. Peng, "Dynamic uniaxial crushing of wood," International Journal of Impact Engineering, vol. 19, no. 5-6, pp. 531-570, 1997.

[8] G. W. Ma, H. Y. Zhou, Y. Lu, and K. Chong, "In-structure shock of underground structures: a theoretical approach," Engineering Structures, vol. 32, no. 12, pp. 3836-3844, 2010.

[9] G. W. Ma, H. Y. Zhou, and K. Chong, "In-structure shock assessment of underground structures with consideration of rigid body motion," Journal of Engineering Mechanics, vol. 137, no. 12, pp. 797-806, 2011.

[10] H. Zhou and G. Ma, "Double-layer floor to mitigate in-structure shock of underground structures: a conceptual design," Engineering Structures, vol. 35, pp. 314-321, 2012.

[11] H. Y. Zhou, M. Beppu, G. W. Ma, and Z. Y. Zhao, "In-structure shock of underground structures: a revisit with experimental investigation," Engineering Structures, vol. 56, pp. 1620-1630, 2013.

[12] S. J. Moon, J. S. Kwak, J. H. Chung et al., "A study on the hybrid mount against vibration and shock for naval ships," Shock and Vibration, vol. 17, no. 3, pp. 269-283, 2010.

[13] N. Jones, Structural Impact, Cambridge University Press, Cambridge, UK, 1989.

[14] F. Zhu, Z. H. Wang, G. X. Lu, and L. M. Zhao, "Analytical investigation and optimal design of sandwich panels subjected to shock loading," Materials \& Design, vol. 30, no. 1, pp. 91-100, 2009.

[15] S. Timoshenko and S. Woinowsky-Krieger, Theory of Plates and Shells, McGraw-Hill, New York, NY, USA, 2nd edition, 1959.

[16] M. A. Biggs, Introduction to Structural Dynamics, McGraw-Hill, New York, NY, USA, 1964.

[17] R. W. Clough and J. Penzien, Dynamics of Structures, McGrawHill, New York, NY, USA, 1993.

[18] U.S. Army Corps of Engineers, Naval Facilities Engineering Command, and and Air Force Civil Engineer Support Agency, "Structures to resist the effects of accidental explosions," UFC 3-340-02, 2008. 

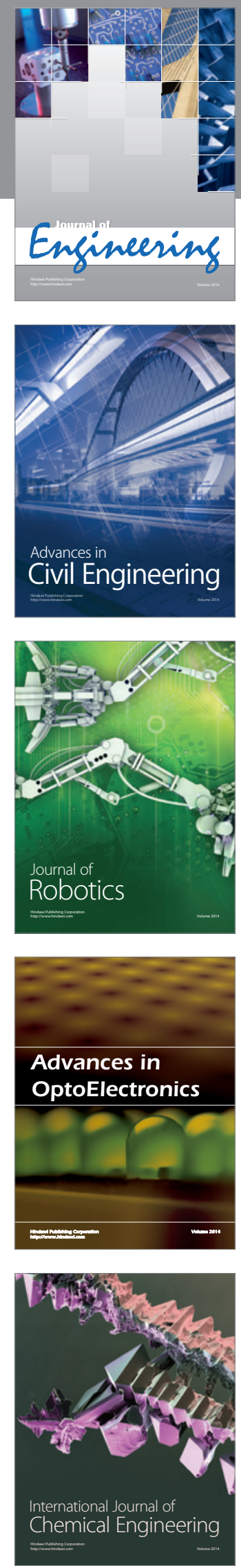

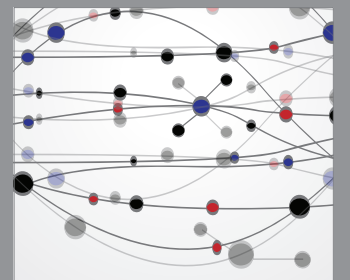

The Scientific World Journal
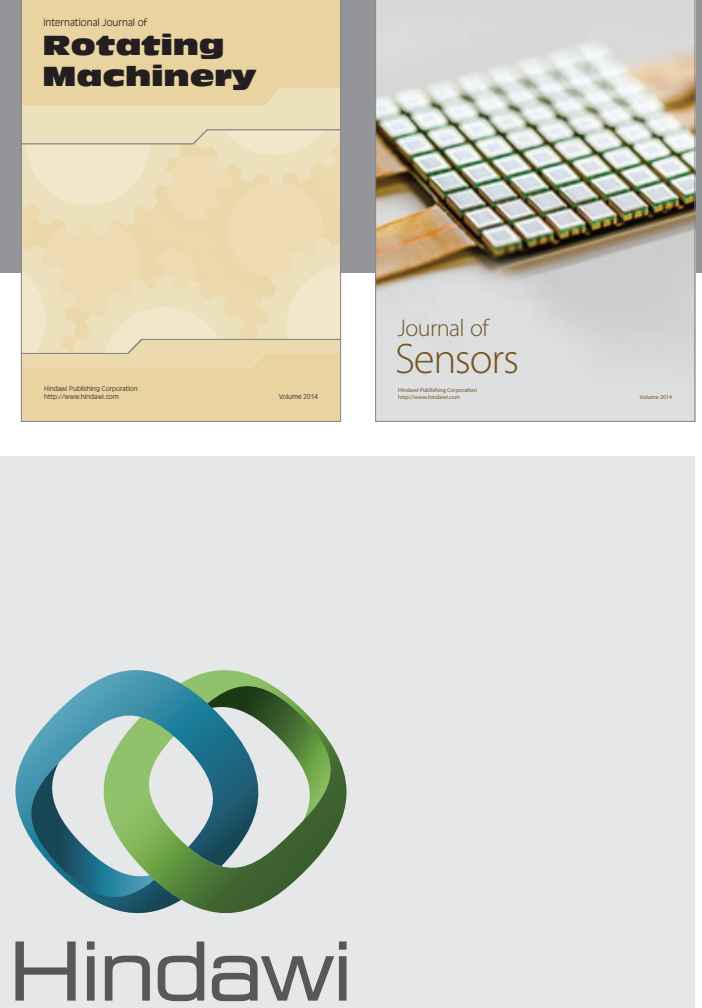

Submit your manuscripts at http://www.hindawi.com
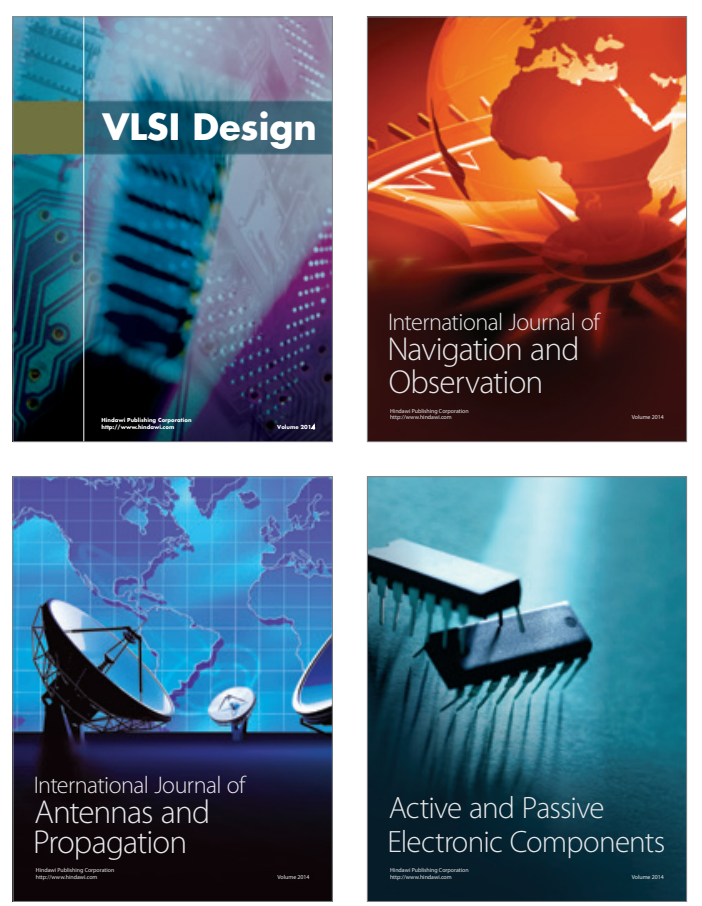
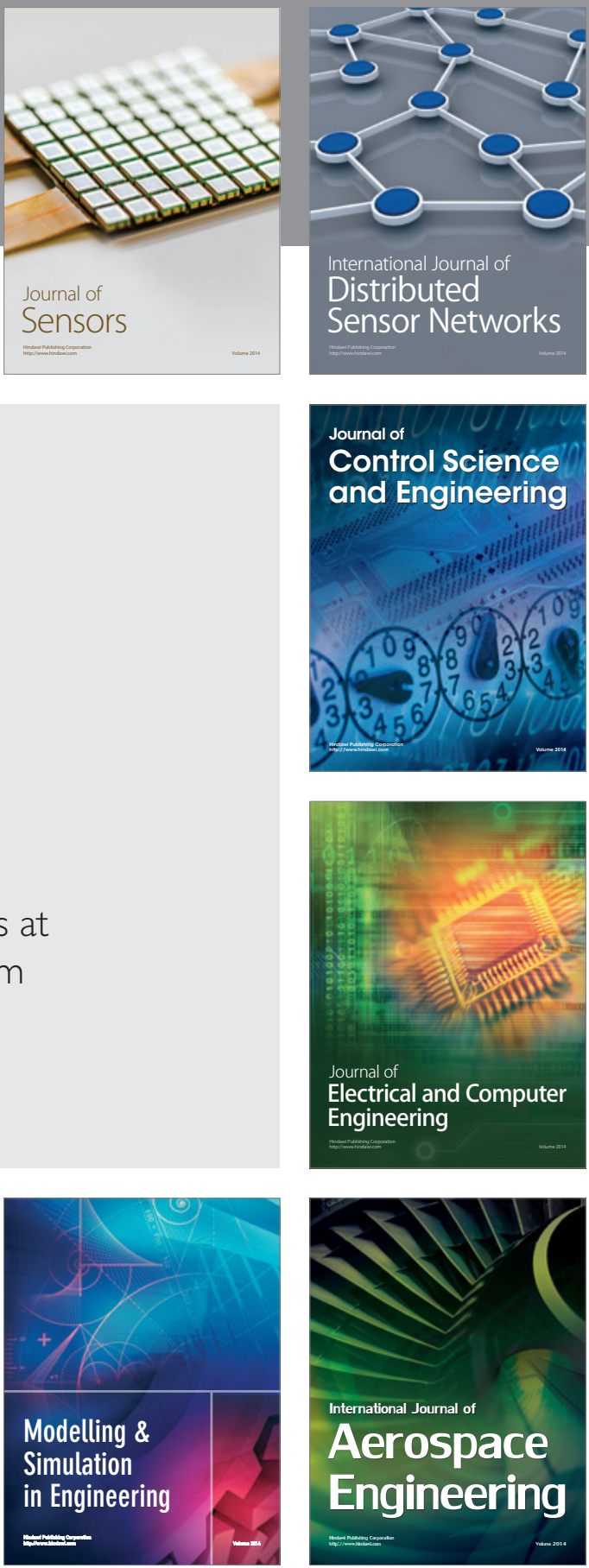

Journal of

Control Science

and Engineering
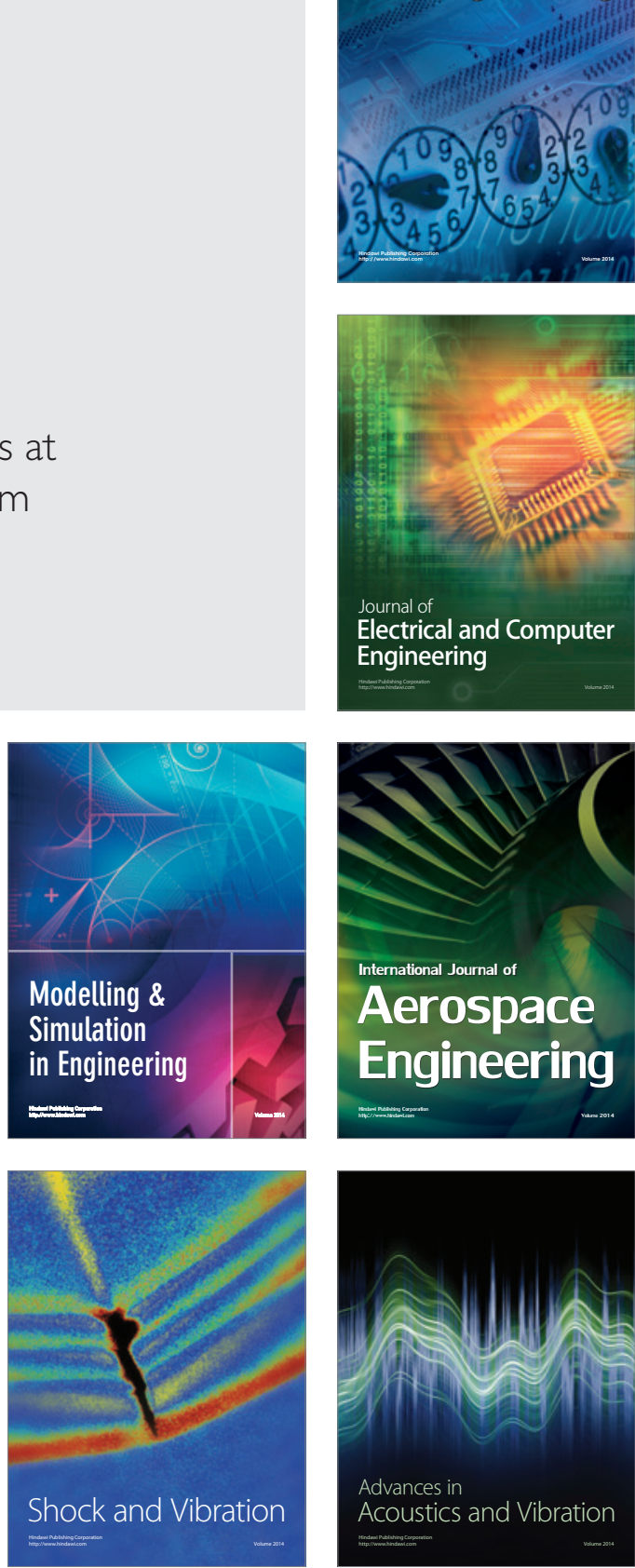